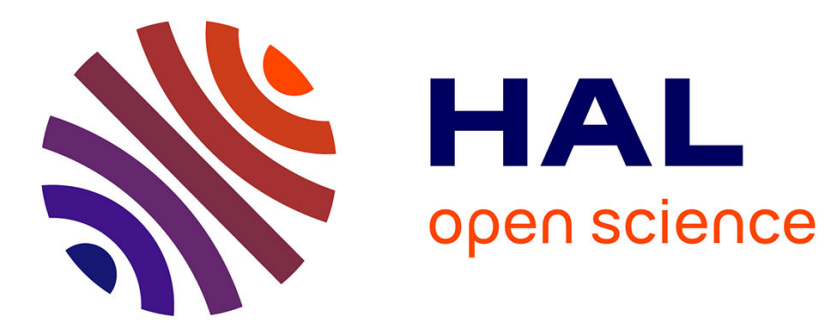

\title{
Complexation of europium(III) by hydroxybenzoic acids: a time-resolved luminescence spectroscopy study
}

Pauline Moreau, Sonia Colette-Maatouk, Pierre Vitorge, Pierre Gareil, Pascal E. Reiller

\section{- To cite this version:}

Pauline Moreau, Sonia Colette-Maatouk, Pierre Vitorge, Pierre Gareil, Pascal E. Reiller. Complexation of europium(III) by hydroxybenzoic acids: a time-resolved luminescence spectroscopy study. Inorganica Chimica Acta, 2015, 432, pp.81-88. 10.1016/j.ica.2015.03.036 . hal-01194523

\section{HAL Id: hal-01194523 \\ https://hal.science/hal-01194523}

Submitted on 7 Sep 2015

HAL is a multi-disciplinary open access archive for the deposit and dissemination of scientific research documents, whether they are published or not. The documents may come from teaching and research institutions in France or abroad, or from public or private research centers.
L'archive ouverte pluridisciplinaire HAL, est destinée au dépôt et à la diffusion de documents scientifiques de niveau recherche, publiés ou non, émanant des établissements d'enseignement et de recherche français ou étrangers, des laboratoires publics ou privés.

\section{(ㅇ)(1) $\$$}

Distributed under a Creative Commons Attribution - NonCommercial - NoDerivatives| 4.0 


\section{Complexation of Europium(III) by Hydroxybenzoic Acids: A Time-Resolved Luminescence Spectroscopy Study}

Pauline Moreau ${ }^{a, \dagger}$, Sonia Colette-Maatouk ${ }^{a, \hbar}$, Pierre Vitorge ${ }^{b}$, Pierre Gareil ${ }^{c}$, Pascal E. Reiller ${ }^{a, *}$

a Commissariat à l'Énergie Atomique et aux énergies alternatives, CE Saclay, CEA/DEN/DANS/DPC/SEARS, Laboratoire de développement Analytique, Nucléaire, Isotopique et Élémentaire, Bâtiment 391 PC 33, F-91191 Gif-sur-Yvette CEDEX, France ${ }^{b}$ Commissariat à l'Énergie Atomique et aux énergies alternatives, CE Saclay, CEA/DEN/DANS/DPC/SECR, Laboratoire de Radiolyse et de la Matière Organique, Bâtiment 391 PC 33, F-91191 Gif-sur-Yvette CEDEX, France. ${ }^{c}$ Chimie Paris-Tech, Laboratory of Physicochemistry of Electrolytes, Colloids, and Analytical Sciences, 11 rue Pierre et Marie Curie, F-75005, Paris, France.

KEYWORDS. Europium; lanthanides; hydroxybenzoic acids; phenolic acids; complexation; Time-resolved Luminescence Spectroscopy

* Corresponding author: Tel: +33 16908 4312; fax: +33 16908 9475. E-mail address: pascal.reiller(at)cea.fr

Present address: ${ }^{\dagger}$ BRGM, Direction des Laboratoires, 3 Avenue Claude Guillemin - BP 36009, 45060 Orléans CEDEX 02, France. ${ }^{\sharp}$ Commissariat à l'Énergie Atomique et aux énergies alternatives, CE Saclay, DEN/DPIE/SA2P, Bâtiment 516P, 91191 Gif-sur-Yvette CEDEX, France. 


\begin{abstract}
.
Complexation of $\mathrm{Eu}(\mathrm{III})$ by two hydroxybenzoic acids, namely $p$-hydroxybenzoic acid (4-dihydroxybenzoic, $\mathrm{HPhbH}$ ), and protocatechuic acid (3,4-dihydroxybenzoic, $\mathrm{HProtoH}_{2}$ ), is studied by time-resolved luminescence spectroscopy (TRLS) in mildly acidic solution. Comparable formation constants are determined at 0.1 mol. $\mathrm{L}^{-1} \mathrm{NaCl}$ for $\mathrm{EuPhbH}^{2+}{ }_{-}$ $\log _{10} \beta^{\circ}\left(\mathrm{EuPhbH}^{2+}\right)=2.18 \pm 0.09(1 \sigma)-$ and $0.01 \mathrm{~mol} \cdot \mathrm{L}^{-1} \mathrm{NaCl}$ for $\mathrm{EuProtoH}_{2}{ }^{2+}-$ $\log _{10} \beta^{\circ}\left(\right.$ EuProtoH$\left._{2}{ }^{2+}\right)=2.72 \pm 0.07(1 \sigma)$. The stoichiometry and carboxylate complexation of the $\mathrm{EuProtoH}_{2}{ }^{2+}$ complex is ascertained by varying both $\mathrm{pH}$ and ligand concentration. The luminescence decay time of $\mathrm{EuPhbH}^{2+}(\tau=107 \pm 5 \mu \mathrm{s})$ is comparable with that of $\mathrm{Eu}\left(\mathrm{H}_{2} \mathrm{O}\right)_{\mathrm{n}}{ }^{3+}$ ( $\tau=110 \pm 3 \mu \mathrm{s}$ ), suggesting that luminescence quenching processes compensate the expected increase in decay time due to the dehydration associated with complexation. For EuProtoH${ }_{2}^{2+}$, the luminescence decay time is even shorter $(\tau=20 \pm 5 \mu \mathrm{s})$, evidencing intricate quenching processes.
\end{abstract}

\title{
1 Introduction
}

The use of lanthanides (Ln), part of the rare earth elements (REEs) family, is increasing in modern industry, e.g., for solid lasers, permanent magnets, microelectronics... Their importance in the understanding of geochemical processes, their presence in the fission products from the nuclear industry and their analogy with some actinides (An) at their +3 oxidation state also justify a better understanding of their environmental chemistry, particularly their behaviour in waters, soils and sediments, and their toxicity [1-4]. For instance, under superficial conditions, REEs are used to trace matter and water transfer, and to understand weathering processes. 
Ln(III) form complexes with naturally organic ligands containing carboxylate and phenolate groups [5-10]. The understanding of the binding processes with these chemical functions is relevant because they occur greatly in nature. These chemical functions are found in decomposition products of lignin, and afterwards in humic and fulvic acids, which also show high interactions with lanthanides $[4,11,12]$. Among these compounds are the hydroxybenzoic acids $p$-hydroxybenzoic acid (4-hydroxybenzoic, $\mathrm{HPhbH}$ ) and protocatechuic acid $(3,4-$ dihydroxybenzoic, $\left.\mathrm{HProtoH}_{2}\right)-\mathrm{HAH}_{\mathrm{n}}$ symbolism was chosen to distinguish the carboxylic proton, on the left hand side, from the phenolic ones, on the right hand side -, the structure of which are shown on Figure 1.
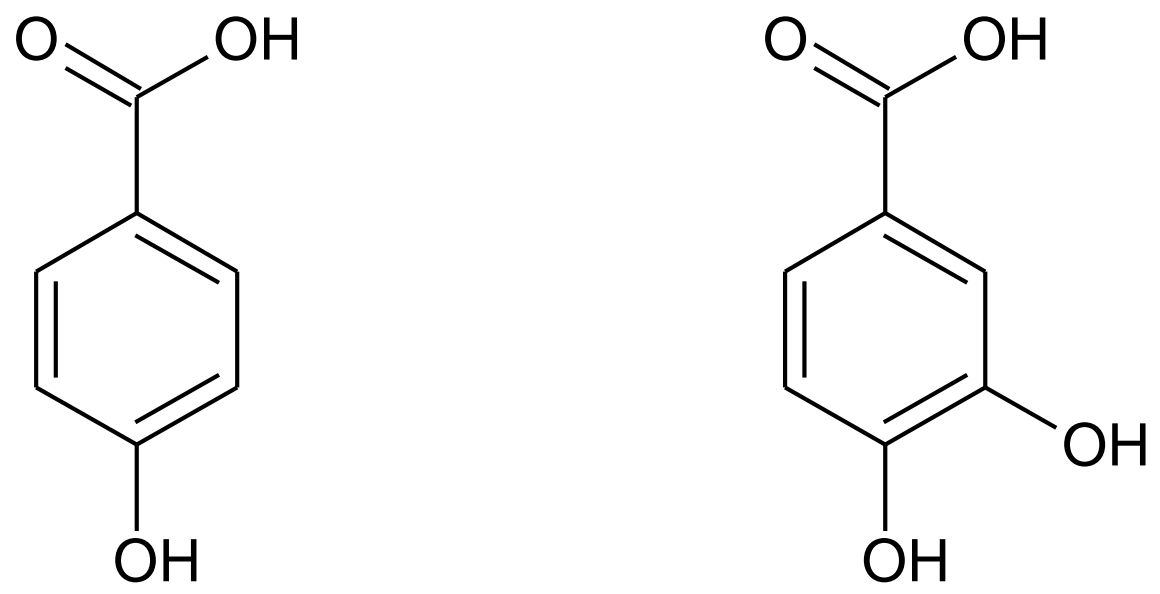

Figure 1. Structures of $\mathrm{HPhbH}$ (left), and $\mathrm{HProtoH}_{2}$ (right).

In the environment, $\mathrm{HPhbH}$ and $\mathrm{HProtoH}_{2}$ were identified in the humus, wood, bark, straw, leaves, and fruit [13-17]. They also have appreciable adsorption properties onto mineral surfaces $[18,19$ and references therein]. The chosen acids only differ from one another by adding an $\mathrm{OH}$-group to the benzoic ring in the meta position with respect to the carboxylate group. 
Europium(III) is a good candidate for complexation studies as it is a non-radioactive analogue of different lanthanides contained in radioactive wastes, and actinides at their +III redox state, e.g. $\mathrm{Pu}(\mathrm{III}), \mathrm{Am}(\mathrm{III})$, and $\mathrm{Cm}(\mathrm{III})$, and has suitable spectroscopic properties [8-10,20-33]. To our knowledge, neither the complexation constants nor the stoichiometries of the complexes between $\mathrm{Eu}(\mathrm{III})$ and $\mathrm{HProtoH}_{2}$ have been determined yet. Only scarce complexation data are available for other metal-HProtoH $\mathrm{H}_{2}$ systems [34,35]. However, the complexation characteristics of Eu(III) with other hydroxybenzoic acids of similar structures have been reported. Wang et al. [24] proposed 1:1 and 1:2 Eu(III)-benzoate complexes from titrations between $p \mathrm{H} 3$ and $5.5\left(\log _{10} \beta_{1}=1.84, \log _{10} \beta_{2}=2.92, I=0.1 \mathrm{~mol}^{-1} \mathrm{~L}^{-1} \mathrm{NaClO}_{4}, 25^{\circ} \mathrm{C}\right)$. The unidentate character was estimated from luminescence decay time analysis. The complexation of Eu(III) or Am(III) with salicylic acid (2-hydroxybenzoic acid) have been studied using potentiometry [5], and time-resolved luminescence spectroscopy (TRLS) [7,10,30,33,36]. A value of $\log _{10} \beta_{1}=2.0 \pm 0.1$ at $I=0.1 \mathrm{~mol} . \mathrm{L}^{-1} \mathrm{NaClO}_{4}, \mathrm{~T}=20^{\circ} \mathrm{C}$ and $p \mathrm{H} 4$, was proposed from TRLS and potentiometry measurements [5,7].

TRLS has been extensively used as a sensitive and selective technique to study complexation of luminescent $\mathrm{Ln}(\mathrm{III})$, especially $\mathrm{Eu}(\mathrm{III})$, by a variety of ligands $[2,9,21,26,37]$. The luminescence spectra and decay times analyses probe the properties of the complexes formed $[20,38]$, and typically allow determining the complexation constants and degree of symmetry [10,37]. Complexation in aqueous solutions is usually associated with an increase of the luminescence decay time. Upon complexation the water molecules that act as luminescence quenchers are expelled from the first hydration sphere of the luminescent cation. The implied increase in decay time has been used to estimate the number of water molecules in the first hydration sphere using empirical relationships [20,22,23,25]. High resolution steady state and 
TRLS studies under cryogenic conditions $(4.7 \mathrm{~K})$ indicated that $\mathrm{Eu}(\mathrm{III})$ binds to $\mathrm{HPhbH}$ through the carboxylic group at $p \mathrm{H} 5$ and that the point symmetry group is $\mathrm{C}_{1}, \mathrm{C}_{2}$ or $\mathrm{C}_{\mathrm{S}}[10]$.

The f-block elements usually give hard cations that form stable complexes with hard donor atoms [39]. Complexation constant values are usually similar along the $\operatorname{Ln}(\mathrm{III})$ series with a slight increase of $\beta_{1}$ due to the Ln contraction [1,40,41].

The aim of this study is to obtain the formation constants and stoichiometries of $\mathrm{Eu}(\mathrm{III})-\mathrm{HPhbH}$ and $-\mathrm{HProtoH}_{2}$ complexes. The complexation equilibria are probed by the changes in the $\mathrm{Eu}(\mathrm{III})$ time-resolved luminescence spectra as a function of ligand concentration at both fixed $p \mathrm{H}$, and varying $p \mathrm{H}$ at fixed ligand concentration. The decay times are also reported and discussed with respect to the quenching effects.

\section{Experimental Section}

\subsection{Preparation of samples.}

All solutions were prepared using freshly purified water $\left(18.2 \mathrm{M} \Omega . \mathrm{cm}^{-1}\right.$, Thermo EASYPURE II, Saint Herblain, France). $\mathrm{HPhbH}, \mathrm{HProtoH}_{2}$, and $\mathrm{NaCl}$ were purchased from Sigma-Aldrich (Saint-Quentin-Fallavier, France). The hydroxybenzoic acid stock solutions were obtained after dissolution in 0.1 or $0.01 \mathrm{~mol} . \mathrm{L}^{-1} \mathrm{NaCl}$ media. Europium(III) stock solution $\left(10^{-3}\right.$ mol. $\mathrm{L}^{-1}$ ) was obtained after the dissolution of $99.99 \% \mathrm{Eu}_{2} \mathrm{O}_{3}$ (Johnson Matthey, Roissy, France) in $3.510^{-3} \mathrm{~mol} . \mathrm{L}^{-1} \mathrm{HCl}$. 


\subsection{Complexation batch samples.}

First, the experiments were carried out at $(20 \pm 1)^{\circ} \mathrm{C}, p \mathrm{H} 5.5$, with fixed concentrations of $\mathrm{Eu}(\mathrm{III}), 10^{-6}$ and $10^{-5} \mathrm{~mol} . \mathrm{L}^{-1}$. The concentration of the acid varied from 0 to $0.048 \mathrm{~mol} . \mathrm{L}^{-1}$, and 0 to $0.092 \mathrm{~mol} . \mathrm{L}^{-1}$ for $\mathrm{HPhbH}$ and $\mathrm{HProtoH}_{2}$, respectively. The ionic strength was fixed at 0.1 and 0.01 mol. $\mathrm{L}^{-1} \mathrm{NaCl}$ for $\mathrm{HPhbH}$ and $\mathrm{HProtoH}_{2}$, respectively. Second, the carboxylate complexation Eu-HProtoH $\mathrm{H}_{2}$ system was checked at varying $p \mathrm{H},[\mathrm{Eu}(\mathrm{III})]=10^{-4} \mathrm{~mol} \cdot \mathrm{L}^{-1}$, $\left[\mathrm{HProtoH}_{2}\right] \approx 0.03 \mathrm{~mol} . \mathrm{L}^{-1}$, and fixed ionic strength $0.1 \mathrm{~mol} . \mathrm{L}^{-1} \mathrm{NaCl}$. Batch samples were left for a 24 hour equilibration time before analysis. The $p \mathrm{H}$ values were measured using a combined glass electrode (Mettler-Toledo, Viroflay, France) connected to a Seven Easy S20 Mettler-Toledo $p \mathrm{H}$ meter. The calibrations were done using commercial buffers (Bioblock Scientitic, $3.99,7.01$, and 10.06 at $20^{\circ} \mathrm{C}$ )

\subsection{Time-resolved luminescence spectroscopy (TRLS).}

The experimental set up has already been described elsewhere [29,31]. During these experiments the average energy at the excitation wavelength (394 nm, vide infra) was less than $1 \mathrm{~mJ}$. The luminescence signal was collected during a gate width $(W)$ of $300 \mu \mathrm{s}$, after an initial delay time $(D)$ of $10 \mu$ s after the excitation laser flash. To increase the signal-to-noise ratio, 300 to 1000 accumulations were performed for each spectrum. It is worthy to note that independent batches of solutions were analysed in a random order. The excitation wavelength was set at $\lambda_{\text {exc }}=394 \mathrm{~nm}$, i.e. in the ${ }^{7} \mathrm{~F}_{0} \rightarrow{ }^{5} \mathrm{~L}_{6}$ transition of $\mathrm{Eu}^{3+}$ [42]. After inner conversion from the ${ }^{5} \mathrm{~L}_{6}$ excited state, only the transitions from the ${ }^{5} \mathrm{D}_{0}$ excited state to the ground ${ }^{7} \mathrm{~F}_{\mathrm{j}}$ manifold are responsible for the recorded luminescence at $D$ greater than $10 \mu$ s $[42,43]$. In the acquisition window, these transitions are the ${ }^{5} \mathrm{D}_{0} \rightarrow{ }^{7} \mathrm{~F}_{0}$ transition $\left(\lambda_{\max } \approx 579 \mathrm{~nm}\right)$, forbidden 
for magnetic and electric reasons, the ${ }^{5} \mathrm{D}_{0} \rightarrow{ }^{7} \mathrm{~F}_{1}$ transition $\left(\lambda_{\max } \approx 592 \mathrm{~nm}\right)$, a magnetic dipole transition, and the ${ }^{5} \mathrm{D}_{0} \rightarrow{ }^{7} \mathrm{~F}_{2}$ transition $\left(\lambda_{\max } \approx 618 \mathrm{~nm}\right.$ ) described as a hypersensitive transition [38] as it is highly correlated to the chemical environment of $\mathrm{Eu}(\mathrm{III})$. For each previously obtained spectrum the background noise was subtracted and the luminescence was divided by the average of the laser energy before and after the acquisition (pyroelectric detector RJ-7610, probe RJ-734, Laser Precision Corp., USA), and by the number of acquisitions (accumulations). In that manner, all the spectra were directly comparable. The stabilities of the acids were tested comparing UV-Visible spectra before and after an $394 \mathrm{~nm}$ laser irradiation, and no differences were obtained (data not shown).

The luminescence decay parameters are obtained from the peak area of either the ${ }^{5} \mathrm{D}_{0} \rightarrow{ }^{7} \mathrm{~F}_{1}$ or ${ }^{5} \mathrm{D}_{0} \rightarrow{ }^{7} \mathrm{~F}_{2}$ transition at varying delay $D$ values with the same gate width $W$. The obtained decay is described by a first order kinetics, and for a purely integrative system like a CCD camera the luminescence signal of a species $i$ is given by equation (1),

$\mathrm{F}_{\mathrm{i}}=\int_{D}^{D+W} \mathrm{~F}_{\mathrm{i}}^{\mathrm{o}} \exp \left(-\frac{\mathrm{t}}{\tau_{\mathrm{i}}}\right) \mathrm{dt}=\mathrm{F}_{\mathrm{i}}^{\mathrm{o}} \tau_{\mathrm{i}} \exp \left(-\frac{D}{\tau_{\mathrm{i}}}\right)\left(1-\exp \left(-\frac{W}{\tau_{\mathrm{i}}}\right)\right)$

where $\mathrm{F}^{\mathrm{o}, \mathrm{i}}$ and $\tau_{\mathrm{i}}$ are the initial luminescence intensity and decay time of the species $i$, respectively; they were obtained by a non-linear fitting of the experimental results $\left(\mathrm{F}_{\mathrm{i}}\right)$, at varying $D$ values (typically $10 \mu$ s steps) to equation (1) as already detailed elsewhere [29,31].

\subsection{Determination of complexation constants by TRLS studies.}

The complexation of $\mathrm{Eu}^{3+}$ with an ionized acid $\mathrm{A}^{-}$is recalled in the Appendix 1 of the supporting information (SI). The ionized carboxylic acid $\mathrm{A}^{-}$stands here for $\mathrm{PhbH}^{-}$and 
ProtoH ${ }_{2}^{-}\left(p K_{\mathrm{a}}^{\circ}\right.$ in Table 1). The peak area ratio between the ${ }^{5} \mathrm{D}_{0} \rightarrow{ }^{7} \mathrm{~F}_{2}$ and the ${ }^{5} \mathrm{D}_{0} \rightarrow{ }^{7} \mathrm{~F}_{1}$ transition - referred as the asymmetry ratio ${ }^{7} \mathrm{~F}_{2} /{ }^{7} \mathrm{~F}_{1}-$ is often used to estimate complexation constants considering that the intensity of the ${ }^{5} \mathrm{D}_{0} \rightarrow{ }^{7} \mathrm{~F}_{1}$ transition is not modified upon complexation $[9,21,36]$. Even if the extent of modification for the ${ }^{5} \mathrm{D}_{0} \rightarrow{ }^{7} \mathrm{~F}_{1}$ transition is much lower compared to the ${ }^{5} \mathrm{D}_{0} \rightarrow{ }^{7} \mathrm{~F}_{2}$ one [44], the non-modification of area under the peaks, and shapes of peaks, is not always verified [26,37,45]. Hence, we adapted an approach where no hypothesis on the ${ }^{5} \mathrm{D}_{0} \rightarrow{ }^{7} \mathrm{~F}_{1}$ transition is made [2,27]. Basic assumptions as well as interim calculations accounting for ionization of the acids and side complexation reactions (hydrolysis and $\mathrm{Cl}^{-}$complexation) are recalled in the SI.

The $\left[\mathrm{EuA}^{2+}\right] /[\mathrm{Eu}(\mathrm{III})]_{\mathrm{nc}}$ experimental concentration ratio, where $[\mathrm{Eu}(\mathrm{III})]_{\mathrm{nc}}$ refers to noncomplexed with hydroxybenzoic acid $\mathrm{Eu}(\mathrm{III})-\mathrm{Eu}(\mathrm{OH})_{\mathrm{n}}^{(3-n)+}$ and mostly $\mathrm{EuCl}_{\mathrm{m}}{ }^{(3-\mathrm{m})+}$ under our conditions, see Table S1 of the SI -, is calculated from the ${ }^{7} \mathrm{~F}_{2} /{ }^{7} \mathrm{~F}_{1}$ experimental ratio, and from the ${ }^{7} \mathrm{~F}_{\mathrm{i}, \mathrm{j}}(\mathrm{i}=1$ or $2, \mathrm{j}=0$ or 1$)$ molar intensities measured at the beginning $\left({ }^{7} \mathrm{~F}_{\mathrm{i}, 0}\right)$ and the end $\left({ }^{7} \mathrm{~F}_{\mathrm{i}, 1}\right)$ of the titration. The experimental $\left[\mathrm{EuA}^{2+}\right] /[\mathrm{Eu}(\mathrm{III})]_{\mathrm{nc}}$ concentration ratio (Equation $\mathrm{S} 9$ of the SI) is reported into the law of mass action yielding equation (2).

$\log _{10} \frac{\left[\mathrm{EuA}^{2+}\right]}{[\mathrm{Eu}]_{\mathrm{nc}}}=\log _{10}{ }^{\mathrm{app}} \beta\left(\mathrm{EuA}^{2+}\right)+\log _{10}\left[\mathrm{~A}^{-}\right]$

The stoichiometry is checked by the linearity of the log-log plot of $\left(\left[\mathrm{EuA}^{2+}\right] /[\mathrm{Eu}(\underline{\mathrm{III}})]_{\mathrm{nc}}\right)$ vs. $\left[\mathrm{A}^{-}\right]$, and by the value of the slope. The complexation constant $\left({ }^{\mathrm{app}} \beta\right)$ is given at the intercept. 


\section{Results and Discussion}

\subsection{Luminescence Spectra}

The time-resolved luminescence (TRL) spectra of $\mathrm{Eu}(\mathrm{III})$, normalized to the area of the ${ }^{5} \mathrm{D}_{0} \rightarrow{ }^{7} \mathrm{~F}_{1}$ transition (trapezoid method between 582 and $605 \mathrm{~nm}$ ), with increasing $\mathrm{HPhbH}$ and HProto $\mathrm{H}_{2}$ concentrations are given in Figure 2. For both acids, the ${ }^{5} \mathrm{D}_{0} \rightarrow{ }^{7} \mathrm{~F}_{0}$ transition appears upon adding the ligand evidencing that the chemical environment of $\mathrm{Eu}(\mathrm{III})$ losses its centrosymmetry upon complexation [46]. The position of the ${ }^{5} \mathrm{D}_{0} \rightarrow{ }^{7} \mathrm{~F}_{0}$ transition is approximately $579 \mathrm{~nm}$. This indicates a low charge of the complexing unit [47] and a low coordination number [48]. Normalizing the spectra to the total area between 570 and $640 \mathrm{~nm}$ permits evidencing isosbestic points (Figure S1 of the SI), and hence the formation of only one complex for each ligand.

As awaited almost no change in the shape of the ${ }^{5} \mathrm{D}_{0} \rightarrow{ }^{7} \mathrm{~F}_{1}$ transition is noted $\left(\lambda_{\max } \approx 592 \mathrm{~nm}\right)$ : there is no noticeable difference between $\mathrm{Eu}(\mathrm{III})-\mathrm{HPhbH}$ and $-\mathrm{HProtoH}_{2}$ (see Figure $\mathrm{S} 2$ of the SI). The net intensity of the ${ }^{5} \mathrm{D}_{0} \rightarrow{ }^{7} \mathrm{~F}_{1}$ increases with $[\mathrm{HPhbH}]_{\text {total }}$ but slightly decreases with $\left[\mathrm{HProtoH}_{2}\right]_{\text {total }}$ (Figure S3 of the SI). The increase in intensity of the ${ }^{5} \mathrm{D}_{0} \rightarrow{ }^{7} \mathrm{~F}_{2}$ hypersensitive transitions on addition of ligands indicates the change in the symmetry around $\mathrm{Eu}(\mathrm{III})$ atom for each complexes (Figure S3 of the SI). The ${ }^{5} \mathrm{D}_{0} \rightarrow{ }^{7} \mathrm{~F}_{2}$ relative intensities and shapes do not seem to be different for Eu(III)-HPhbH and $-\mathrm{HProtoH}_{2}\left({ }^{7} \mathrm{~F}_{2}{ }^{7} \mathrm{~F}_{1} \approx 3, \lambda_{\max } \approx 616 \mathrm{~nm}\right.$, Figure 2 and Figure S2 of the SI) given the noisy signal obtained for the latter complex. Comparison of the different transition intensities and shapes indicates a very similar symmetry for both complexes. No assignment of point symmetry group can be done given the noisy character of the spectra. 


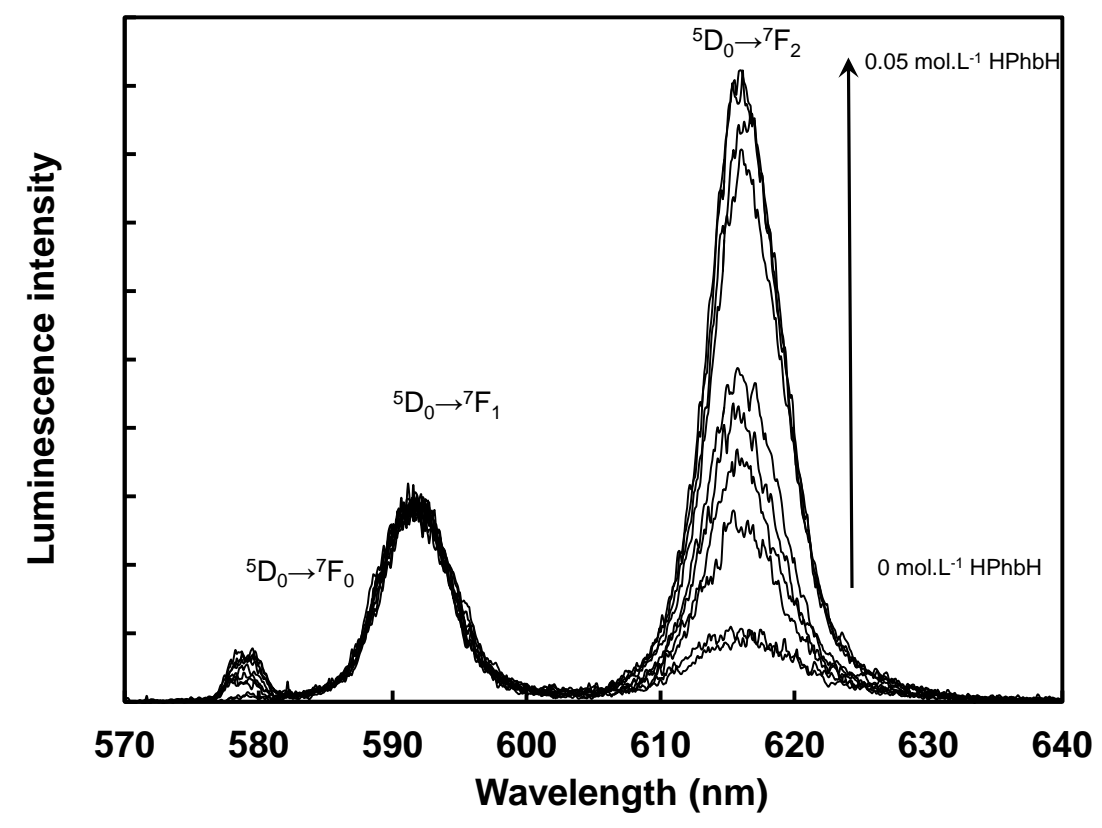

a

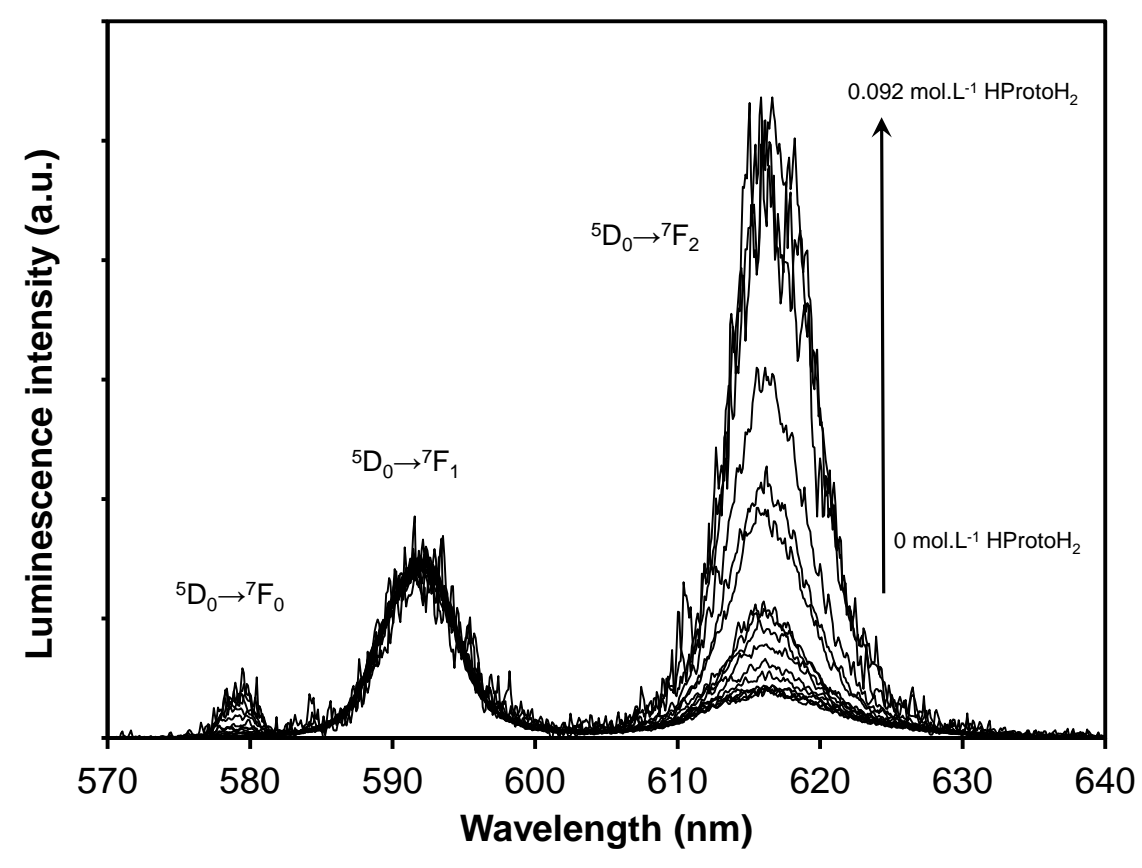

Figure 2. Normalized time-resolved luminescence spectra of $\mathrm{Eu}(\mathrm{III})$ complexed with $\mathrm{HPhbH}$ (a) and $\mathrm{HProtoH}_{2}$ (b) the intensities were normalized to the area of the ${ }^{5} \mathrm{D}_{0} \rightarrow{ }^{7} \mathrm{~F}_{1}$ transition for the sake of comparison; $D=10 \mu \mathrm{s}, W=300 \mu \mathrm{s}$, $[\mathrm{Eu}(\mathrm{III})]=10^{-6} \mathrm{~mol} \cdot \mathrm{L}^{-1}, I=0.1 \mathrm{~mol} \cdot \mathrm{L}^{-1} \mathrm{NaCl}$, $p \mathrm{H}$ 5.5; The thick black lines represent uncomplexed $\mathrm{Eu}^{3+}$. 


\subsection{Complexation constant determination.}

The luminescence spectra evolutions were taken as complexometric titration. The formation of $\mathrm{EuA}_{\mathrm{i}}^{(3-\mathrm{i})+}$ is considered to be complete as both TRL spectra and decay times are no longer modified after further additions of acid. In that respect, the solubility of $\mathrm{HPhbH}$ is not enough to reach the titration end-point. Consequently, the end-point was determined by fitting experimental data with equation (S1) to (S9) for a 1:1 complex.

The initial luminescence of the ${ }^{5} \mathrm{D}_{0} \rightarrow{ }^{7} \mathrm{~F}_{1}$ and ${ }^{5} \mathrm{D}_{0} \rightarrow{ }^{7} \mathrm{~F}_{2}$ transitions was determined for each sample using equation (1). Plot of equation (2) is presented in Figure 3. Parallel straight lines with slopes close to unity - i.e. $0.9_{4} \pm 0.0_{4}$ for $\mathrm{HPhbH}, 1.0 \pm 0.1$ for $\mathrm{HProtoH}_{2}-$ were obtained for the two acids. This confirms that only one complex of 1:1 stoichiometry is formed under these conditions for both $\mathrm{EuPhbH}^{2+}$ and $\mathrm{EuProtoH}_{2}{ }^{2+}$. The $\log _{10} \beta_{1}$ at the intercept values are summarized in Table 1 together with otherwise published data for similar complexes [7,9,24,49-56].

Extrapolation to zero ionic strength of the complexation constants were applied using an extended Debye-Hückel expression using the parameters tabulated in Kielland [57] in agreement with the used thermodynamic data in Hummel et al. [58]. The $\mathrm{PhbH}^{-}$and $\mathrm{ProtoH}_{2}^{-}$ parameters, $a_{i}=6$ and $b=0$, were taken from other aromatic acids in analogy [57]. The determined apparent constants with the unity slope are $\log _{10}{ }^{\text {app }} \beta\left(\mathrm{EuPhbH}^{2+}\right)=1.53 \pm 0.07$ $(1 \sigma)$ and $\log _{10}{ }^{\text {app }} \beta^{\circ}\left(\right.$ EuProtoH$\left._{2}{ }^{2+}\right)=2.46 \pm 0.07(1 \sigma)$. Accounting for chloride complexation, the constant at the experimental ionic strengths are $\log _{10} \beta^{0.1 \mathrm{M}}\left(\mathrm{EuPhbH}^{2+}\right)=1.72 \pm 0.09(1 \sigma)$ and $\log _{10} \beta^{0.01 \mathrm{M}}\left(\mathrm{EuProtoH}_{2}{ }^{2+}\right)=2.49 \pm 0.07(1 \sigma)$. Finally, the extrapolated thermodynamic 
constant values at $I=0$ are $\log _{10} \beta^{\circ}\left(\mathrm{EuPhbH}^{2+}\right)=2.18 \pm 0.09(1 \sigma)$ and $\log _{10} \beta^{\circ}\left(\right.$ EuProtoH $\left._{2}{ }^{2+}\right)=$ $2.72 \pm 0.07(1 \sigma)$ in the framework of Kielland's model [57].

The use of the specific ion theory (SIT) implies analogy with $\mathrm{Am}^{3+}$ data in Guillaumont et al. [59], and requires the estimation of the value of $\varepsilon\left(\mathrm{Eu}^{3+}, \mathrm{A}^{-}\right)$. The compilation of Eu(III)-acetate $[9,49-52,54,56]$ and Am(III)-acetate [55] data from literature in SI gives $\log _{10} \beta^{\circ}\left(\mathrm{EuPhbH}^{2+}\right)=$ $2.30 \pm 0.09$ and $\log _{10} \beta^{\circ}\left(\right.$ EuProtoH $\left._{2}{ }^{2+}\right)=2.73 \pm 0.07$.

The slight differences between the values of the two close formation constants are not straightforward to interpret. One may think about the differences between the $p K_{\mathrm{a}}$ of the acids, but the linear free-energy relationships are not always exactly followed (vide post). 


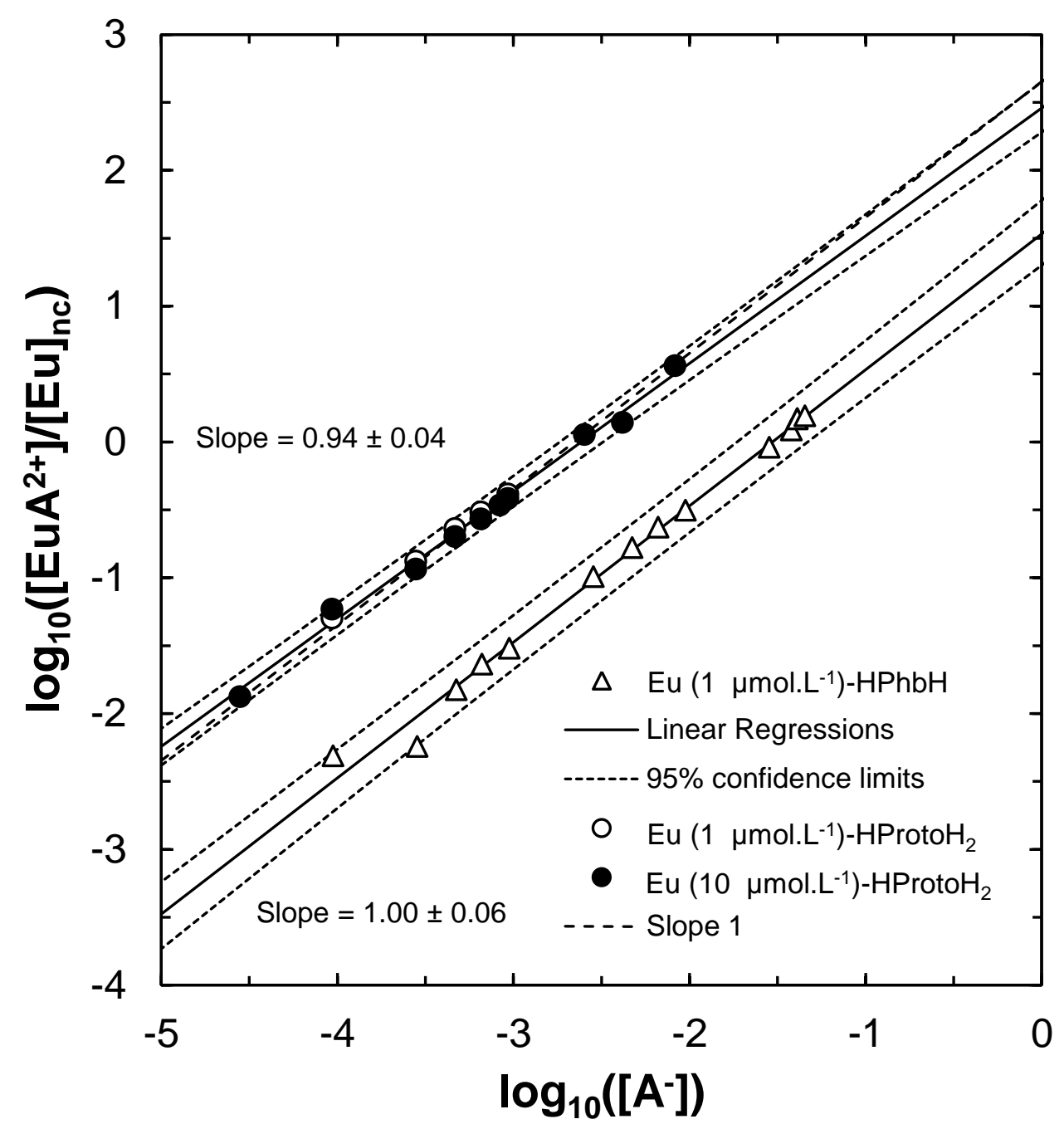

Figure 3. Determination of Eu(III) complex stoichiometries and formation constants from

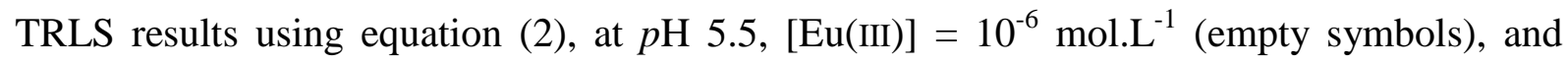
$[\mathrm{Eu}(\mathrm{III})]=10^{-5} \mathrm{~mol} \cdot \mathrm{L}^{-1}$ (filled symbol), for $\mathrm{EuPhbH}^{2+}$ (triangles, $\left.I=0.1 \mathrm{~mol} . \mathrm{L}^{-1} \mathrm{NaCl}\right)$, EuProtoH $_{2}{ }^{2+}$ (circles, $\left.I=0.01 \mathrm{~mol} . \mathrm{L}^{-1} \mathrm{NaCl}\right)$.

The possibility of a complex with the catechol functionality could eventually be raised, even if it can be postulated that higher $\lambda_{\max }$ of the ${ }^{5} \mathrm{D}_{0} \rightarrow{ }^{7} \mathrm{~F}_{0}$ transition should be observed due to the chelate formation and due to a higher charged complex $[47,48]$. This kind of complex was proposed for $\mathrm{Al}(\mathrm{III})$ complexed by cathecol [60], caffeic acid - 3-(3,4-dihydroxyphenyl) 
2-propenoic acid - [61,62], gallic acid [63], and $\mathrm{HProtoH}_{2}[61,64]$, but not for the less hydrolysable and softer $\mathrm{Pb}$ (II) complexed by caffeic acid [65]. It also worthy to note that lanthanides do not seem to form significant catechol complexes at $p \mathrm{H}$ lower than 6 [66]. Given the agreement between $\log _{10} \beta^{\circ}$ in the correlation in Figure 6, it is likely that $\mathrm{Eu}(\mathrm{III})$ is forming a complex with the carboxylate function, but the verification of this kind of chelate formation is desirable by verifying the $p \mathrm{H}$ dependence of the complexation.

The formation of such catechuic complexes would yield,

$\mathrm{M}^{z+}+n \mathrm{H}^{+}+$Proto $^{3-} \rightleftarrows \mathrm{H}_{\mathrm{n}} \operatorname{Proto}^{(z+n-3)+}$

in the case of protocatechuic acid, $\mathrm{M}^{z+}$ would be complexed by the catechuic function, and the carboxylic proton remains acidic $(n=0$ or 1$)$

Given the second and third $\mathrm{p} K_{\mathrm{a}} \mathrm{s}$ of protocatechuic acid, the formation of such complexes in our case would lead to $\log _{10} \beta^{\circ}{ }_{1}=-7.3$ for,

$\mathrm{Eu}^{3+}+\mathrm{HProtoH}_{2}=\mathrm{HProtoEu}^{+}+2 \mathrm{H}^{+}$

and $\log _{10} \beta^{\circ}{ }_{1}=13$ for

$\mathrm{Eu}^{3+}+$ Proto $^{3-} \rightleftarrows$ ProtoEu $^{0}$

A verification of the EuProtoH${ }_{2}^{2+}$ stoichiometry has been done at $[\mathrm{Eu}(\mathrm{III})]=10^{-4} \mathrm{~mol} \cdot \mathrm{L}^{-1}$, [Proto] $=0.03$ mol. $\mathrm{L}^{-1}$, ionic strength $0.1 \mathrm{~mol} . \mathrm{L}^{-1} \mathrm{NaCl}$, and varying $p \mathrm{H}$.that should lead to a half reaction point at $p \mathrm{H} c a .4$ as seen in the predominance and repartition diagrams in Figure 4a,b calculated using Phreeplot $[67,68]$. From the formation constants of the catechol 
complexes of lanthanides [66], the half-reaction point between $\mathrm{Eu}^{3+}$ and potentially $\mathrm{HProtoEu}^{+}$and $\mathrm{ProtoEu}^{0}$ are awaited at $p \mathrm{H} c a .5$ and 6 , respectively - see predominance and repartition diagrams in Figure S4 of the SI. The normalized spectra are shown in Figure 5a and asymmetry ratio in Figure S5 of the SI. Using equation (2), the calculated $\log _{10} \beta=2.27 \pm$ 0.06 for the 1:1 complex (Figure 5b), gives $\log _{10} \beta^{\circ}\left(\right.$ EuProtoH $\left._{2}{ }^{2+}\right)=2.72 \pm 0.07$ using Kielland's model [57]. This is in perfect agreement with the value determined at fixed $p \mathrm{H}$, and the half reaction point $c a .4$ indicates the formation of $\mathrm{EuProtoH}_{2}{ }^{2+}$.
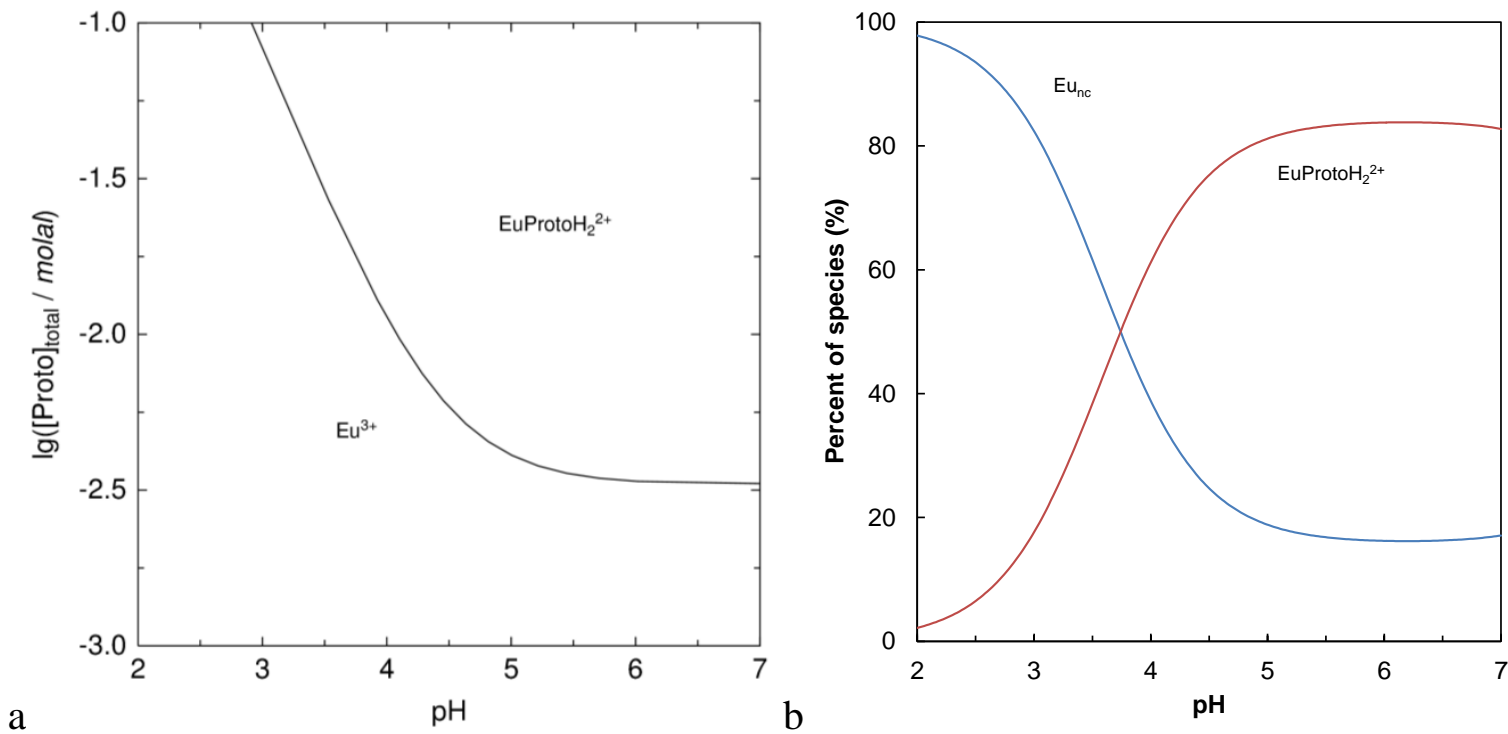

Figure 4. Predominance plot of the Eu(III)/Proto system at $[\mathrm{Eu}(\mathrm{III})]=10^{-4} \mathrm{~mol} \cdot \mathrm{L}^{-1}$ and $I=0.1$ mol. $\mathrm{L}^{-1} \mathrm{NaCl}$ (a), and repartition plot of the $\mathrm{Eu}(\mathrm{III}) /$ Proto system under $\mathrm{EuProtoH}_{2}{ }^{2+}$ hypothesis (b) $-\mathrm{Eu}(\mathrm{III})_{\mathrm{nc}}$ is defined in the text and SI. 

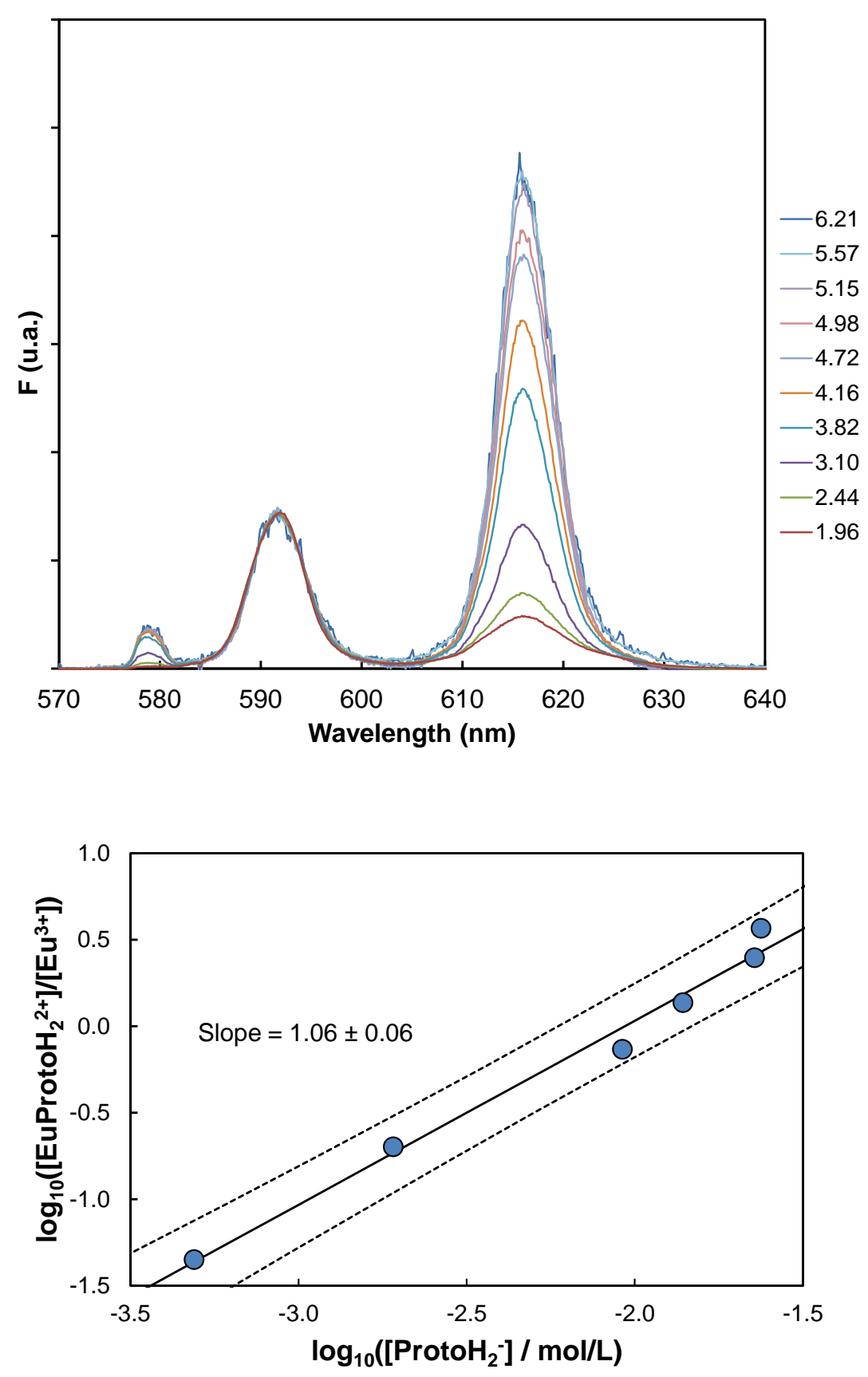

Figure 5. Normalized time-resolved luminescence spectra of Eu(III) complexed with $\mathrm{HProtoH}_{2}$ at varying $p \mathrm{H}$ (a), and determination of $\mathrm{Eu}(\mathrm{III})$ complex stoichiometries and formation constants from TRLS results using equation (2), at varying $p \mathrm{H}$ (b); the intensities were normalized to the area of the ${ }^{5} \mathrm{D}_{0} \rightarrow{ }^{7} \mathrm{~F}_{1}$ transition for the sake of comparison; $D=10 \mu \mathrm{s}$, $W=300 \mu \mathrm{s},[\mathrm{Eu}(\mathrm{III})]=10^{-4} \mathrm{~mol} . \mathrm{L}^{-1},\left[\mathrm{HProtoH}_{2}\right]_{\mathrm{tot}} \approx 0.03 \mathrm{~mol} . \mathrm{L}^{-1}, I=0.1 \mathrm{~mol} \cdot \mathrm{L}^{-1} \mathrm{NaCl}$. 


\subsection{Comparison with other ligands}

Linear free energy relationships between $\log _{10} \beta^{\circ}{ }_{1}$ and the $p K_{\mathrm{a}}$ of the ligands have been proposed for organic ligands [69] including lanthanides [5,53,56,70,71], and for complexation of various lanthanides(III) and actinides(III) by inorganic small ligands with O-donor atoms, as typically $\mathrm{SO}_{4}{ }^{2-}$ or $\mathrm{CO}_{3}{ }^{2-}$ (red dotted line in Figure 6) proposed by Vitorge et al. [72]. $\mathrm{Am}^{3+}$, which can be considered as an analogue of $\mathrm{Eu}^{3+}$ for O-donor ligands, complexes with $\mathrm{H}_{2} \mathrm{PO}_{4}^{-}$, $\mathrm{SiO}(\mathrm{OH})_{3}{ }^{-}$, and even the very weak $\mathrm{NO}_{3}{ }^{-}$complex - taken from the critically assessed thermodynamic data base in Guillaumont et al. [59] -, following the Hoffmeister's series, also fall onto this latter correlation. Data for $\mathrm{Eu}(\mathrm{III})$ complexes with $\mathrm{NO}_{3}{ }^{-}, \mathrm{H}_{2} \mathrm{PO}_{4}{ }^{-}$, and $\mathrm{CO}_{3}{ }^{2-}$ [73] are also very close to this correlation. These relationships occur for ligands that show very similar structure, and are seldom exactly followed [69].

These kinds of correlations were proposed for the complexation of $\mathrm{Ln}$ (III) with aromatic (poly)carboxylic acids and the sum of $p K_{a}$ [24,71]. This correlation, recalled in Figure 6 (circles, plain line) corrected to 0 ionic strength using Davies equation [74], shows a less steeper slope than the one obtained for inorganic O-donor ligands. If one only considers the non-chelate ligands, the slope is even much steeper (blue circles, dotted line), which is in agreement with the awaited comportment for chelates [75]. It appears that the thermodynamic constants of $\mathrm{Eu}(\mathrm{III})$ and $\mathrm{Am}(\mathrm{III})$ with other non-chelate aromatic organic acids from literature $[5,9,53,70,71]$ in Table 1 , are in fair agreement with both previous correlation with (poly)carboxylic aromatic ligands. Eu(III)-acetic and -chloroacetic acid complexes - estimated in SI from literature data [9,49-53,76] using the SIT [59] - are also in fair agreement with the proposed correlations. Nevertheless, it can be see that the increase of $\log _{10} \beta$ with $p K_{\mathrm{a}}$ values is not exactly followed as stressed by Irving and Rossotti [69]. 
Interestingly, $\log _{10} \beta^{\circ}$ for $\mathrm{EuPhbH}^{2+}$ and $\mathrm{EuProtoH}_{2}{ }^{2+}$ fall into the dispersion of this group when only considering the $p K_{\mathrm{a}}$ of the carboxylic function. This means that the para and meta OH-groups do not seem to influence the complexation mechanism under our $p \mathrm{H}$ conditions. There is no possibility of a chelate formation that would include the carboxylate function, and the perturbation of the acidity of the carboxylate function is rather weak (see Table 1). Conversely, complexation constants with $o$-hydroxybenzoic acid - (Eu,Am)(III)-salicylic acid [5,7,36] - and overall $\alpha$-hydroxyphenylacetic acid - Eu(III)-mandelic acid [5] -, and lactic acid [77] that can form five-membered chelates are slightly above the trend, which is in agreement with the general stabilities of the chelates [75]. The particular case of lactic acid was revised recently, and $p K$ of the $\mathrm{OH}$ group should be taken into account [78]. In the case of $o$-methoxybenzoic and $\alpha$-methoxyphenylacetic acid complexes the thermodynamic constants are closer to the correlation [5] as the five-membered chelates cannot form. 
Table 1. First $\mathrm{p} K_{\mathrm{a}}$ values of the organic acids and formation constants for their $1: 1$ complex with $\mathrm{Eu}(\mathrm{III})$, or Am(III) when noted.

\begin{tabular}{|c|c|c|c|c|c|c|c|c|c|}
\hline Acid & ${\mathrm{p} K \mathrm{a}^{\circ}(I=0)}$ & Ref & $\log _{10} \beta_{1}$ & $\log _{10} \beta^{\circ}{ }_{1}$ & $I\left(\mathrm{~mol} . \mathrm{L}^{-1}\right)$ & $\mathrm{T}(\mathrm{K})$ & & Technique & Ref \\
\hline $\mathrm{HPhbH}$ & 4.58 & $\mathrm{a}$ & $1.72 \pm 0.09$ & $2.18 \pm 0.09$ & 0.1 & 293 & & TRLS & $\mathrm{f}$ \\
\hline $\mathrm{HProtoH}_{2}$ & 4.49 & $\mathrm{a}$ & $2.49 \pm 0.07$ & $2.72 \pm 0.07$ & 0.01 & 293 & & TRLS & $\mathrm{f}$ \\
\hline \multirow[t]{3}{*}{ Acetic acid } & $4.76 \pm 0.002$ & $\mathrm{~b}$ & & $2.81 \pm 0.07$ & 0 & 298 & or & & $\mathrm{g}$ \\
\hline & & & & & & 293 & & & \\
\hline & & & & $2.5 \pm 0.2$ & 0 & 298 & & $\begin{array}{l}\text { Solvent } \\
\text { extraction }\end{array}$ & $\mathrm{h}$ \\
\hline Propionic acid & 4.87 & $\mathrm{~b}$ & 1.98 & 2.24 & 2 & 298 & & pot & $\mathrm{i}$ \\
\hline Isobutyric acid & 4.86 & & 1.98 & 2.24 & 2 & 298 & & & \\
\hline Benzoic acid & $4.20 \pm 0.003$ & $\mathrm{~b}$ & & $2.5 \pm 0.2$ & & 298 & & TRLS & $\mathrm{j}$ \\
\hline $\begin{array}{l}\text { o-methoxybenzoic } \\
\text { acid }\end{array}$ & 4.13 & $\mathrm{c}$ & $2.28 \pm 0.02$ & $2.92 \pm 0.02$ & 0.1 & 298 & & pot & $\mathrm{c}$ \\
\hline \multirow[t]{4}{*}{ Salicylic acid } & $2.97 \pm 0.00$ & $\mathrm{~b}$ & & $2.7 \pm 0.05$ & & 293 & & $\mathrm{pot} / \mathrm{cal}$ & $\mathrm{c}$ \\
\hline & & & & $2.8 \pm 0.2$ & & & & TRLS & $\mathrm{k}$ \\
\hline & & & $1.84 \pm 0.08$ & 2.47 & 0.1 & 298 & & TRLS & d \\
\hline & & & $1.53 \pm 0.13$ & 2.48 & 1 & & & & \\
\hline Phenylacetic acid & $4.00 \pm 0.03$ & $\mathrm{e}$ & & $2.9 \pm 0.3$ & 0.1 & n.m. & & TRLS & 1 \\
\hline & & & & $2.1 \pm 0.02$ & & 298 & & $\mathrm{pot} / \mathrm{cal}$ & $\mathrm{e}$ \\
\hline $\begin{array}{l}\alpha \text {-methoxyphenyl- } \\
\text { acetic acid }\end{array}$ & 3.18 & $\mathrm{c}$ & $2.17 \pm 0.02$ & $2.81 \pm 0.02$ & 0.1 & & & pot & $\mathrm{c}$ \\
\hline Chloroacetic acid & 2.83 & $\mathrm{~m}$ & & 1.8 & 2 & 298 & & pot/cal & $\mathrm{m}$ \\
\hline Dichloroacetic acid & 1.3 & $\mathrm{~m}$ & & 1.7 & 2 & 298 & & $\mathrm{pot} / \mathrm{cal}$ & $\mathrm{m}$ \\
\hline
\end{tabular}

TRLS/pot/cal, determination using TRLS, potentiometry, and calorimetry, respectively. ${ }^{a}$ Erdemgil et al. [79]; ${ }^{\mathrm{b}}$ Smith \&

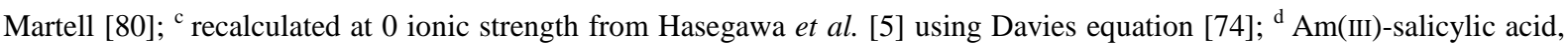
Barkleit et al. [36]; ${ }^{\mathrm{e}}$ Hasegawa et al. [6]; ${ }^{\mathrm{f}}$ this work; ${ }^{\mathrm{g}}$ compilation of data for Eu(III)-acetate complex $[9,49-52,54,56]$ (for calculation details, see Appendix 2, Table S2, and Figure S6 of the SI); ${ }^{\mathrm{h}}$ Am(III)-acetic acid from Moore et al. [55], extrapolated at 0 ionic strength using the specific interaction theory (for calculation details, see Appendix 2, Table S2, and Figure S6 of the SI); ${ }^{\mathrm{i}}$ recalculated at 0 ionic strength from Choppin and Graffeo [70] using the acetate complex parameters determined in Appendix 2 of SI; ${ }^{j}$ recalculated at 0 ionic strength from Wang et al. [24] using Davies equation [74]; ${ }^{\mathrm{k}}$ recalculated at 0 ionic strength using Davies equation [74] from Aoyagi et al. [7]; ${ }^{1}$ recalculated at 0 ionic strength from Plancque et al. [9] using Davies equation [74]; ${ }^{\mathrm{m}}$ recalculated at 0 ionic strength from Ensor and Choppin [53] using the acetate complex parameters determined in Appendix 2 of SI; n.m., not mentioned by the authors. 


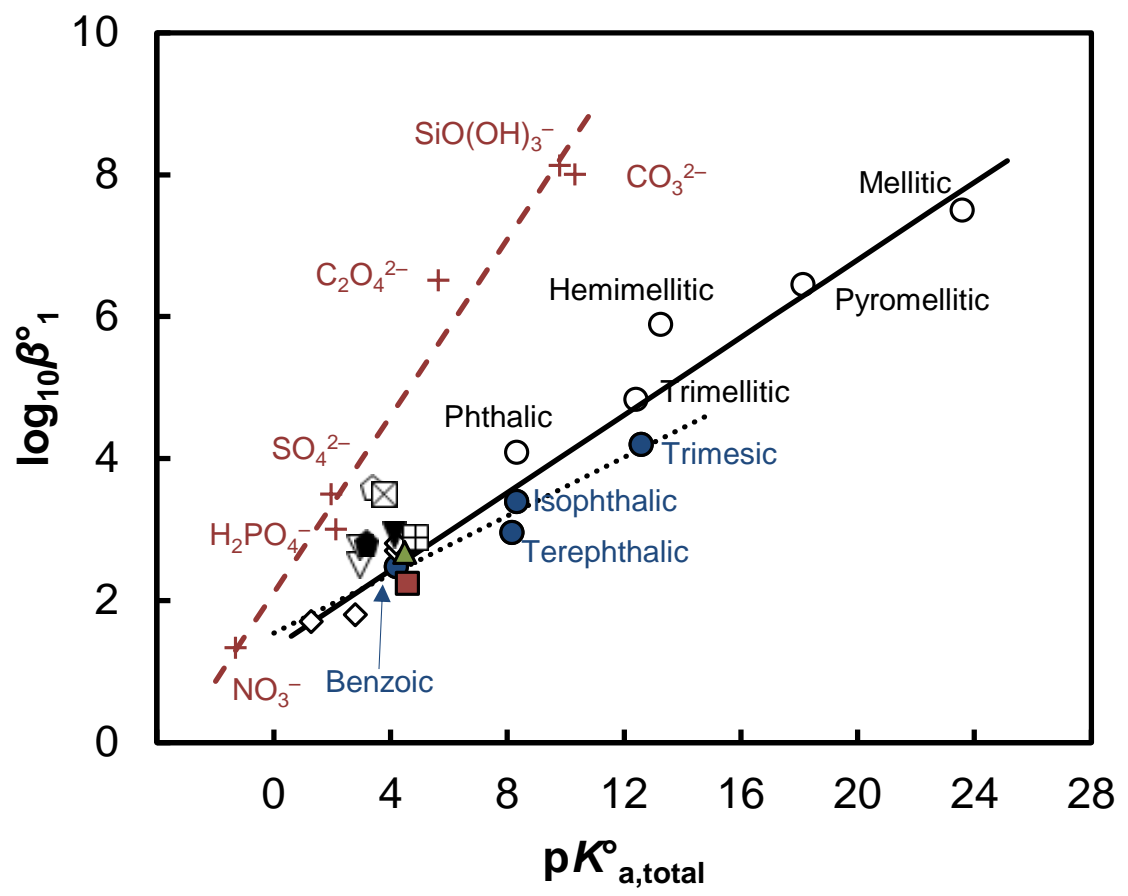

Figure 6. Linear free energy relationships between $\log _{10} \beta^{\circ}{ }_{1}$ and $p K_{\mathrm{a}}{ }^{\circ}$ for complexation of $\mathrm{AmSO}_{4}{ }^{+}, \mathrm{AmCO}_{3}{ }^{+}, \mathrm{AmH}_{2} \mathrm{PO}_{4}{ }^{2+}, \mathrm{AmC}_{2} \mathrm{O}_{4}{ }^{+}, \mathrm{AmSiO}(\mathrm{OH})_{3}{ }^{2+}$, and $\mathrm{AmNO}_{3}{ }^{2+}$ (red cross from $[59,81]$, dashed line is the linear correlation), experimental results from this study $\left(\mathrm{EuProtoH}_{2}{ }^{2+}\right.$ green triangle, and $\mathrm{EuPhbH}^{2+}$ red square), data from aromatic (poly)carboxylic acids [24] (blue circles are non-chelate, open circles are possible chelates), $\mathrm{Eu}^{3+}$ complexes with acetic/chloroacetic (from SI), and phenylacetic acid (from [6,9] in Table 1, open diamonds); complex of $\mathrm{Eu}^{3+}$ with propionic acid [70] (straight-crossed square); complexes of $\mathrm{Am}^{3+}$ or $\mathrm{Eu}^{3+}$ with salicylic [5,7,36] (open inversed triangles), and $\mathrm{Eu}(\mathrm{III})$ with o-methoxybenzoic (closed inversed triangle), mandelic (2-hydroxy-2-phenylacetic acid, open pentagon), $\alpha$-methoxyphenylacetic (closed pentagon) acids [5], and lactic acid (tilted-crossed square) [77] are shown for comparison; the plain line is the correlation in ref. [24] between $\log _{10} \beta^{\circ}$ and $\mathrm{p} K_{\text {total }}^{\circ}$ recalculated at 0 ionic strength using Davies equation [74]; the dotted line is the correlation accounting only for the non-chelate ligands (blue circles). 


\subsection{Luminescence decay}

The variations of the $\mathrm{Eu}(\mathrm{III})$ luminescence decay times for $\mathrm{EuPhbH}^{2+}$ and $\mathrm{EuProtoH}_{2}{ }^{2+}$ as a function of ionized ligand concentration calculated using the ${ }^{5} \mathrm{D}_{0} \rightarrow{ }^{7} \mathrm{~F}_{1}$ transition are given in Figure 7 - calculation on the ${ }^{5} \mathrm{D}_{0} \rightarrow{ }^{7} \mathrm{~F}_{2}$ transition are showing comparable results. The decay time for $\mathrm{EuPhbH}^{2+}(\tau=107 \pm 5 \mu \mathrm{s})$ is comparable to the one for $\mathrm{Eu}\left(\mathrm{H}_{2} \mathrm{O}\right)_{\mathrm{n}}{ }^{3+}-$ typically $\tau_{\mathrm{Eu}^{3+}}=$ $(110 \pm 5) \mu \mathrm{s}$ [20]. Upon complexation with $\mathrm{HProtoH}_{2}$ the luminescence decay of EuProtoH${ }^{2+}$ is even faster than that of $\mathrm{Eu}\left(\mathrm{H}_{2} \mathrm{O}\right)_{\mathrm{n}}{ }^{3+}$ reaching $\tau=(20 \pm 5) \mu \mathrm{s}$. This was not unexpected since it has already been reported that the decay times of Eu(III)-phenylacetate [9] (50 $\mu \mathrm{s})$ and -salicylate [30,33] $(90 \mu \mathrm{s})$ complexes are faster than $\tau_{\mathrm{Eu}\left(\mathrm{H}_{2} \mathrm{O}_{n}\right)^{3+}}$. Nevertheless, as for the inorganic ligands $[20,25]$, most of Eu(III) complexes with other carboxylates have shown an increase in the decay time, which originates from the departure of water molecules from the first hydration sphere after addition of ligand $[8,9,20,24,30,78,82]$. 


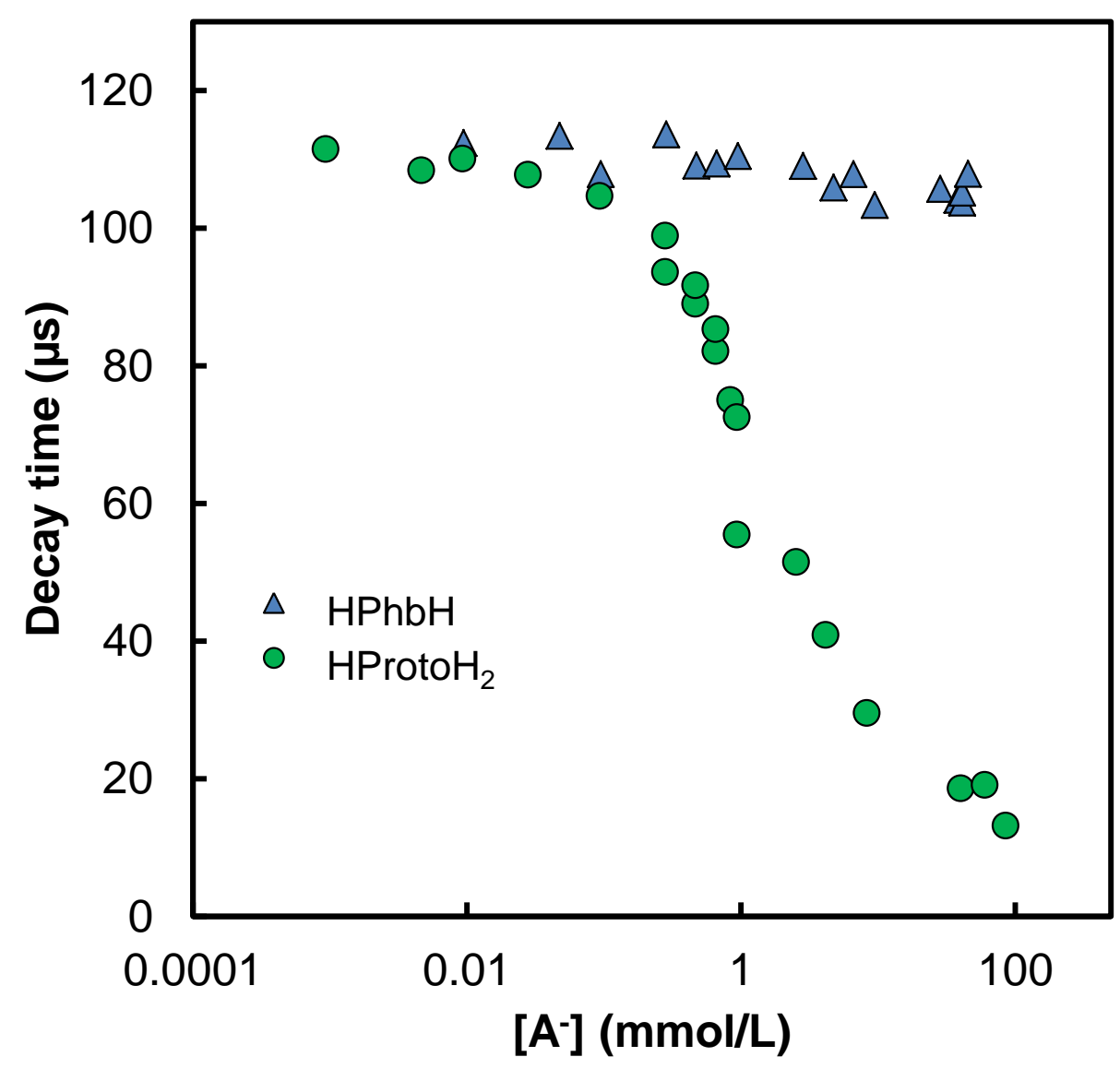

Figure 7. Decay time of $\mathrm{Eu}(\mathrm{III})$ at $p \mathrm{H} 5.5$ as a function of ionized ligand concentrations $\left(\mathrm{A}^{-}\right.$ stands for $\mathrm{PhbH}^{-}$and $\mathrm{ProtoH}_{2}^{-}, \mathrm{p} K_{\mathrm{a}}$ in Table 1): $\mathrm{PhbH}^{-}$(triangles, $[\mathrm{Eu}(\mathrm{III})]=10^{-6}$ mol. $\mathrm{L}^{-1}, I=$ $\left.0.1 \mathrm{~mol} . \mathrm{L}^{-1} \mathrm{NaCl}\right)$ and $\operatorname{ProtoH}_{2}^{-}\left(\right.$circles, $\left.[\mathrm{Eu}(\mathrm{III})]=10^{-5} \mathrm{~mol} \cdot \mathrm{L}^{-1}, I=0.01 \mathrm{~mol} \cdot \mathrm{L}^{-1} \mathrm{NaCl}\right)$.

According to kinetics theory, during a complexometric titration in TRLS, two different species $-\mathrm{Eu}\left(\mathrm{H}_{2} \mathrm{O}\right)_{\mathrm{n}}{ }^{3+}$ and the complex, or two different complexes - should lead to two different excited states and to a bi-exponential decay [83], except if Eu(III) is exchanging faster than observation time between free and bound ligand. For instance, Rao et al. [84] only seem to observe one decay time when their pyridine monocarboxylate ligands seem to form several successive complexes with $\mathrm{Eu}(\mathrm{III})$. 
Upon complexation with $\mathrm{PhbH}^{-}$, the obtained luminescence decay can be interpreted as monoexponential because the decay of free and complexed $\mathrm{Eu}(\mathrm{III})$ are very close and cannot be distinguished by our fitting procedure using equation (1). The Stern-Volmer plot,

$$
\frac{\tau_{0}}{\tau}=1+k_{q} \tau_{0}\left[\mathrm{~A}^{-}\right]
$$

where $\tau$ and $\tau_{0}$ are the decay times with and without quenching species, respectively, does not vary significantly from 1 (Figure 8a). Nevertheless, the mechanism does not seem to be a purely static quenching as the luminescence of $\mathrm{Eu}(\mathrm{III})$ increases with total $\mathrm{HPhbH}$ concentration (Figure S3 of the SI). A non-radiative de-excitation pathway, operating in $\mathrm{EuPhbH}^{2+}$ complex, seems to mostly compensate the awaited increase in decay time. This result is consistent with the one evidenced by Barkleit et al. in the case of Am(III) complexed with small organic acids [32], and of Hilder et al. who showed that no Eu(III) luminescence was observed for $\mathrm{Eu}(\mathrm{PhbH})_{3}\left(\mathrm{H}_{2} \mathrm{O}\right)$ complex in the solid state [85].

The decrease in the $\mathrm{Eu}(\mathrm{III})$ decay time in the presence of $\mathrm{HProtoH}_{2}$ may indicate that the complexed acid provides a more efficient non-radiative de-excitation pathway for Eu(III) fluorescence than $\mathrm{H}_{2} \mathrm{O}$, in addition to the other radiative and non-radiative pathways [25].

The Stern-Volmer plot (Figure $8 b$ ) does not show a straight line over the whole $\mathrm{HProtoH}_{2}$ concentration range.

Using the second form of equation (3),

$$
\frac{1}{\tau}=\frac{1}{\tau_{0}}+k_{q}\left[\mathrm{~A}^{-}\right]
$$




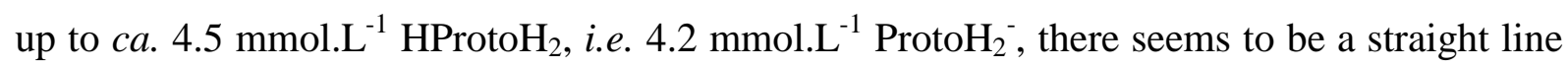
evolution with $k_{\mathrm{q}}=(3.8 \pm 0.4) 10^{6} \mathrm{~L} \mathrm{~mol}^{-1} \mathrm{~s}^{-1}$ and $\tau_{0}=(104 \pm 6) \mu \mathrm{s}$, which can represent the quenching of $\mathrm{Eu}^{3+}$ by ProtoH$_{2}^{-}$. At higher concentration, a second evolution is visible where the $\mathrm{EuProtoH}_{2}{ }^{2+}$ complex is formed and increasing ProtoH $_{2}^{-}$quenches the EuProtoH${ }^{2+}$ luminescence. A $k_{\mathrm{q}}=(5 \pm 1) 10^{5} \mathrm{~L} \mathrm{~mol}^{-1} \mathrm{~s}^{-1}$ and $\tau_{0}=(34 \pm 7) \mu \mathrm{s}$ can be calculated. A comparable evolution has been noted in $\mathrm{UO}_{2}{ }^{2+} /$ anionic surfactant systems around the critical micellar concentration evidencing a change in the quenching of U(VI) associated to micelles $[86,87]$. Under our conditions, a change in the organization of the medium is unlikely, but a relative protection of $\mathrm{Eu}(\mathrm{III})$ from the quenching of $\mathrm{ProtoH}_{2}{ }^{-}$can be considered. This dynamic quenching mechanism is likely of a charge transfer origin as the absorption spectrum of $\mathrm{HProtoH}_{2}$ does not overlap the emission spectrum of $\mathrm{Eu}(\mathrm{III})$.

In the case of the $\operatorname{ProtoH}_{2}^{-}$, the quenching is so important that the luminescence of $\mathrm{Eu}^{3+}$ becomes undetectable, and only mono-exponential decay is measured. As recalled earlier, for strong complexes like dipicolinic acid [88], two decay times are observed [83], one can also think that the observed mono-exponential decays are the consequence of the lability (fast exchange) of the EuProto $\mathrm{H}_{2}{ }^{2+}$ complex.

Assuming a linear dependence between the number of water molecules in the first hydration sphere and the radiative constant $k=1 / \tau$ [22,23], it could be inferred that no water molecule should be expelled from the first coordination sphere of Eu(III) upon addition of $\mathrm{HPhbH}$ and $\mathrm{HProtoH}_{2}$ and that $\mathrm{EuPhbH}^{2+}$ and $\mathrm{EuProtoH}_{2}{ }^{2+}$ would form outer-sphere complexes, which is very unlikely in view of the ${ }^{7} \mathrm{~F}_{2} /{ }^{7} \mathrm{~F}_{1}$ asymmetry ratio (vide ante), and thermodynamic parameters of other carboxylic ligands [70,71]. Moreover, the validity of these relationships 
was not tested in this particular system and the more complete relationships proposed otherwise should be used instead [20,25].

This evidences a complex process for $\mathrm{Eu}(\mathrm{III})$ luminescence quenching by the hydroxybenzoic acids that has never been observed to our knowledge on such large concentration scales. Charge transfer has been proposed for Eu(III)-humate [28] and -salicylate complexes [33] to explain the quenching. The latter authors showed non-trivial energy transfers in the Eu(III)-salicylate system. Kuke et al. [30] found a decay time of $80 \mu$ s for the Eu(III)-salicylate complex with [Salicylic acid]:[Eu(III)] of $3: 1$ at $p \mathrm{H} 5$ and showed that luminescence quenching cannot be attributed to regular $\mathrm{OH}-$ mechanism. They also showed that additional ligand specific quenching contributions have to be taken into account in the case of Eu(III)-salicylic acid complex. 


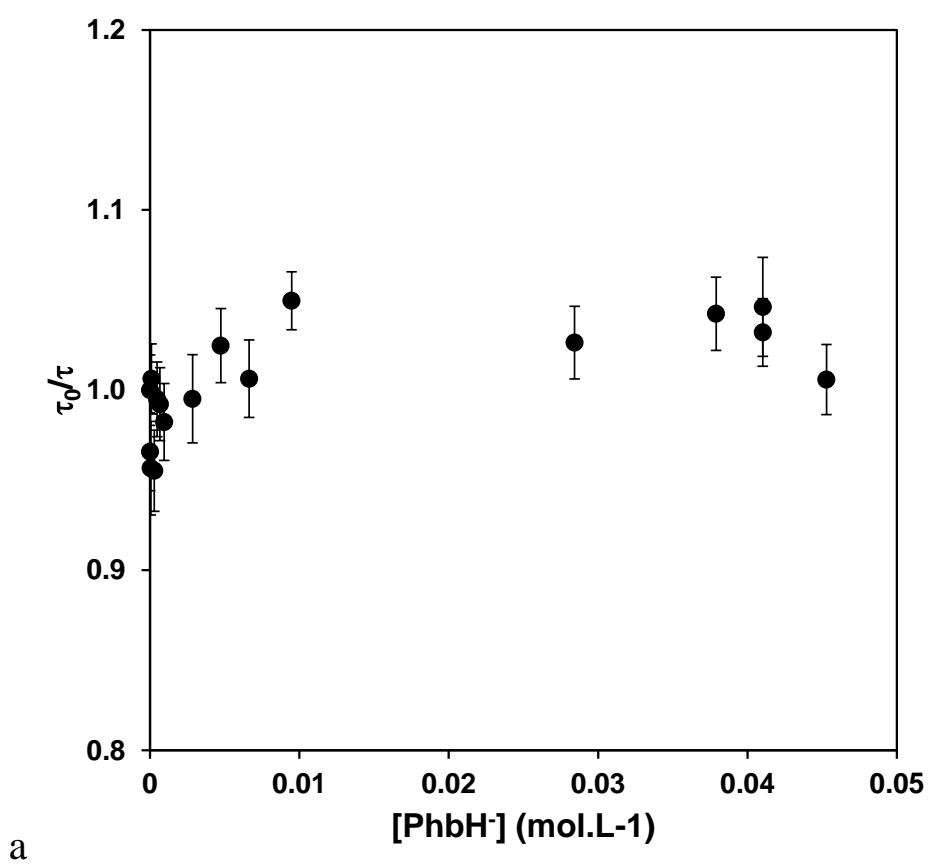

a

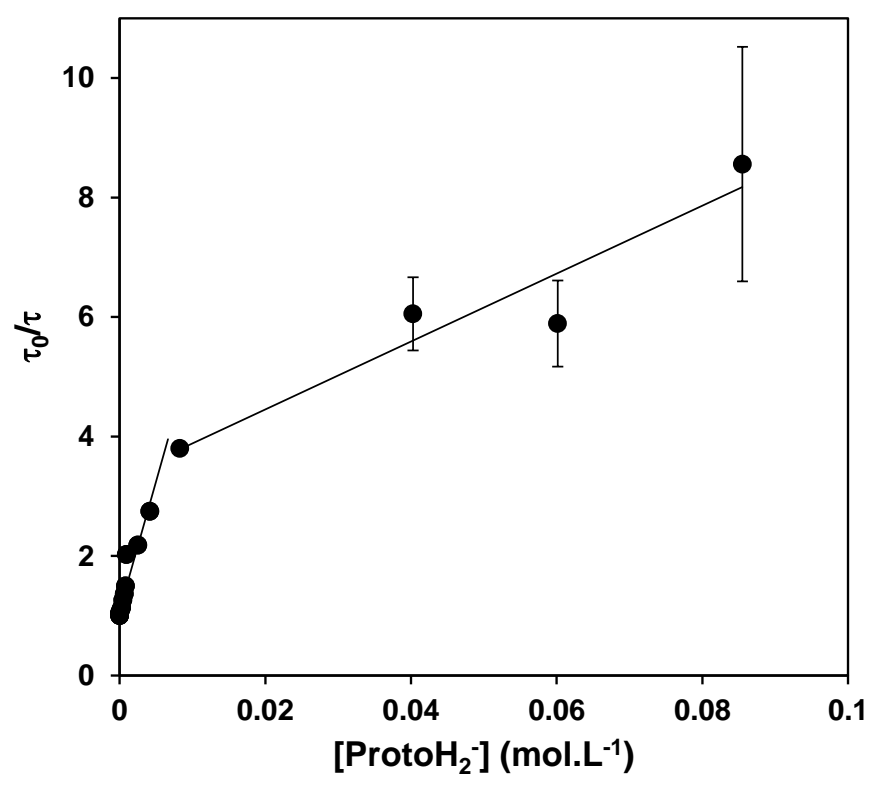

Figure 8. Stern-Volmer plot for $[\mathrm{Eu}(\mathrm{III})]=10^{-5} \mathrm{~mol} \cdot \mathrm{L}^{-1}, \mathrm{pH} 5.5$, for (a) $\mathrm{HPhbH}, I=0.1$ mol. $\mathrm{L}^{-1}(\mathrm{NaCl})$, and (b) $\mathrm{H}_{2} \mathrm{ProtoH}_{2} I=0.01$ mol. $\mathrm{L}^{-1}(\mathrm{NaCl})$. Error bars are $2 \sigma$ calculated from the propagation of error of the fitted $\tau$ values 


\section{Conclusions}

The hydroxybenzoic acids studied, $\mathrm{HPhbH}$ and $\mathrm{HProtoH}_{2}$, clearly form 1:1 complexes with $\mathrm{Eu}(\mathrm{III})$ of similar stabilities for $\mathrm{EuPhbH}^{2+}$ and $\mathrm{EuProtoH}_{2}{ }^{2+}$. The obtained thermodynamic constants are in good agreement with other comparable mono-carboxylic acids. The phenolic groups do not seem to have a marked influence on the complexation. The structures of these complexes are very similar from TRLS spectra. The analyses of the decay times revealed that complex quenching processes are occurring for the two complexes, which prevented the evaluation of the number of water molecules that are expelled from the first hydration sphere.

Supporting Information. Two appendices, six Figures and two Tables. Recall of the method of complexation constant determination using time-resolved luminescence spectroscopy. Stability and solubility constants for Eu(III) complexes and solids. TRLS spectra normalized to the total signal between 570 and $640 \mathrm{~nm}$. Comparison of normalized spectra of the final complexes for $\mathrm{Eu}(\mathrm{III})-\mathrm{HPhbH}$ and $-\mathrm{HProtoH}_{2}$ systems. Compared evolutions of the luminescence of $\mathrm{Eu}(\mathrm{III})-\mathrm{HPhbH}$ and $-\mathrm{HProtoH}_{2}$ systems during complexometric titrations. Theoretical predominance diagram for $\mathrm{HProtoEu}^{+}$and $\mathrm{ProtoEu}^{0}$ complexes. Plot of asymmetry ratios for EuProtoH ${ }_{2}{ }^{+}$complex at varying $p \mathrm{H}$. Data selection of $\mathrm{EuCH}_{3} \mathrm{COO}^{2+}$ and $\mathrm{AmCH}_{3} \mathrm{COO}^{2+}$ complexation constants. Extrapolation to zero ionic strength of $\log _{10} \beta^{\circ}\left(\mathrm{EuCH}_{3} \mathrm{COO}^{2+}\right)$ and $\log _{10} \beta^{\circ}\left(\mathrm{AmCH}_{3} \mathrm{COO}^{2+}\right)$.

Acknowledgements. Daniel Léonço is acknowledged for his participation in TRLS experiment at fixed $p \mathrm{H}$ for $\mathrm{Eu}(\mathrm{III})-\mathrm{HProtoH}_{2}$ system. This work was supported by the RSTB program (RBPCH project) from CEA, and the French Direction Générale de l'Armement (DGA). 


\section{References}

[1] R.H. Byrne, E.R. Sholkovitz, Marine chemistry and geochemistry of the lanthanides, in: Gschneidner, K. A., Jr., L. Eyring (Eds.) Handbook on the Physics and Chemistry of Rare Earths, Vol. 23, Elsevier, 1996, pp. 497-593.

[2] T. Vercouter, B. Amekraz, C. Moulin, E. Giffaut, P. Vitorge, Inorg. Chem., 44 (2005) $7570-7581$.

[3] P. Censi, E. Tamburo, S. Speziale, P. Zuddas, L.A. Randazzo, R. Punturo, A. Cuttitta, P. Arico, J. Hazard. Mater., 186 (2011) 1103-1110.

[4] P.E. Reiller, G. Buckau, Significance of natural organic matter for actinide mobility in the environment, in: C. Poinssot, H. Geckeis (Eds.) Radionuclide Behaviour in the Natural Environment: Science, Implications and Lessons for the Nuclear Industry (ISBN 9780857091321), Woodhead Publishing Ltd., 2012, pp. 103-160.

[5] Y. Hasegawa, Y. Morita, M. Hase, M. Nagata, Bull. Chem. Soc. Jpn., 62 (1989) 14861491.

[6] Y. Hasegawa, N. Yamazaki, S. Usui, G.R. Choppin, Bull. Chem. Soc. Jpn., 63 (1990) 2169-2172.

[7] N. Aoyagi, T. Toraishi, G. Geipel, H. Hotokezaka, S. Nagasaki, S. Tanaka, Radiochim. Acta, 92 (2004) 589-593.

[8] T. Stumpf, T. Fanghanel, I. Grenthe, J. Chem. Soc., Dalton Trans., (2002) 3799-3804. 
[9] G. Plancque, Y. Maurice, V. Moulin, P. Toulhoat, C. Moulin, Appl. Spectrosc., 59 (2005) 432-441.

[10] B. Marmodée, J.S. de Klerk, F. Ariese, C. Gooijer, M.U. Kumke, Anal. Chim. Acta, 652 (2009) 285-294.

[11] J.W. Tang, K.H. Johannesson, Geochim. Cosmochim. Acta, 67 (2003) 2321-2339.

[12] K.H. Johannesson, J.W. Tang, J.M. Daniels, W.J. Bounds, D.J. Burdige, Chem. Geol., 209 (2004) 271-294.

[13] S. Kuwatsuka, H. Shindo, Soil Sci. Plant Nutr., 19 (1973) 219-227.

[14] H. Shindo, S. Kuwatsuka, Soil Sci. Plant Nutr., 21 (1975) 215-225.

[15] K. Suominen, V. Kitunen, A. Smolander, Eur. J. Soil Sci., 54 (2003) 287-293.

[16] D.R. Bedgood, A.G. Bishop, P.D. Prenzler, K. Robards, Analyst, 130 (2005) 809-823.

[17] F.A. Hassan, A. Ismail, A. Abdulhamid, A. Azlan, J. Agric. Food Chem., 59 (2011) 9102-9111.

[18] C.R. Evanko, D.A. Dzombak, J. Colloid Interface Sci., 214 (1999) 189-206.

[19] P. Moreau, S. Colette-Maatouk, P. Gareil, P.E. Reiller, Colloids Surf. A, 435 (2013) $97-$ 108.

[20] W.D. Horrocks, Jr., D.R. Sudnick, J. Am. Chem. Soc., 101 (1979) 334-340. 
[21] J.C. Dobbs, W. Susetyo, F.E. Knight, M.A. Castles, L.A. Carreira, L.V. Azarraga, Anal. Chem., 61 (1989) 483-488.

[22] T. Kimura, G.R. Choppin, J. Alloys Compd., 213 (1994) 313-317.

[23] T. Kimura, Y. Kato, J. Alloys Compd., 278 (1998) 92-97.

[24] Z.M. Wang, L.J. van de Burgt, G.R. Choppin, Inorg. Chim. Acta, 293 (1999) 167-177.

[25] R.M. Supkowski, W.D. Horrocks, Jr., Inorg. Chim. Acta, 340 (2002) 44-48.

[26] S. Colette, B. Amekraz, C. Madic, L. Berthon, G. Cote, C. Moulin, Inorg. Chem., 43 (2004) 6745-6751.

[27] T. Vercouter, Complexes aqueux de lanthanides (III) et actinides (III) avec les ions carbonates et sulfates. Etude thermodynamique par spectrofluorimétrie laser résolue en temps et spectrométrie de masse à ionisation électrospray, $\mathrm{PhD}$ Thesis, Evry-Val d'Essonne, Evry, 2005, pp. 253.

[28] M.U. Kumke, S. Eidner, T. Kruger, Environ. Sci. Technol., 39 (2005) 9528-9533.

[29] J. Brevet, F. Claret, P.E. Reiller, Spectrochim. Acta, Part A, 74 (2009) 446-453.

[30] S. Kuke, B. Marmodée, S. Eidner, U. Schilde, M.U. Kumke, Spectrochim. Acta, Part. A, 75 (2010) 1333-1340.

[31] P.E. Reiller, J. Brevet, Spectrochim. Acta, Part A, 75 (2010) 629-636. 
[32] A. Barkleit, G. Geipel, M. Acker, S. Taut, G. Bernhard, Spectrochim. Acta, Part A, 78 (2011) 549-552.

[33] P.A. Primus, M.U. Kumke, J. Phys. Chem. A, 116 (2012) 1176-1182.

[34] C.R. Jejurkar, I.P. Mavani, Bhattach.Pk, Indian J. Chem., 10 (1972) 1190-1192.

[35] R. Aydin, U. Ozer, Chem. Pharm. Bull., 52 (2004) 33-37.

[36] A. Barkleit, M. Acker, G. Bernhard, Inorg. Chim. Acta, 394 (2013) 535-541.

[37] A.S. Chauvin, S. Comby, B. Song, C.D.B. Vandevyver, F. Thomas, J.-C.G. Bünzli, Chem.-Eur. J., 13 (2007) 9515-9526.

[38] C.K. Jørgensen, B.R. Judd, Mol. Phys., 8 (1964) 281-290.

[39] R.G. Pearson, J. Am. Chem. Soc., 85 (1963) 3533-3539.

[40] R.D. Shannon, Acta Crystallogr. A, 32 (1976) 751-767.

[41] P. d'Angelo, A. Zitolo, V. Migliorati, G. Chillemi, M. Duvail, P. Vitorge, S. Abadie, R. Spezia, Inorg. Chem., 50 (2011) 4572-4579.

[42] W.T. Carnall, P.R. Fields, K. Rajnak, J. Chem. Phys., 49 (1968) 4450-4455.

[43] M.D. Marcantonatos, M. Deschaux, J.J. Vuilleumier, J. Chem. Soc., Faraday Trans. II, 80 (1984) 1569-1598.

[44] P.K. Gallagher, J. Chem. Phys., 41 (1964) 3061-3069. 
[45] A. Heller, A. Barkleit, G. Bernhard, Chem. Res. Toxicol., 24 (2011) 193-203.

[46] J.-C.G. Bünzli, Luminescent Probes, in: J.-C.G. Bünzli, G.R. Choppin (Eds.) Lanthanides Probes in Life, Chemical and Earth Sciences - Theory and Practice, Elsevier, Amsterdam, 1989, pp. 219-293.

[47] M. Albin, W.D. Horrocks, Jr., Inorg. Chem., 24 (1985) 895-900.

[48] G.R. Choppin, Z.M. Wang, Inorg. Chem., 36 (1997) 249-252.

[49] I. Grenthe, Acta Chem. Scand., 16 (1962) 1695-1712.

[50] R.S. Kolat, J.E. Powell, Inorg. Chem., 1 (1962) 293-296.

[51] P.G. Manning, C.B. Monk, Trans. Faraday Soc., 58 (1962) 938-941.

[52] G.R. Choppin, J.K. Schneider, J. Inorg. Nucl. Chem., 32 (1970) 3283-3288.

[53] D.D. Ensor, G.R. Choppin, J. Inorg. Nucl. Chem., 42 (1980) 1477-1480.

[54] A.V. Zotov, B.R. Tagirov, I.I. Diakonov, K.V. Ragnarsdottir, Geochim. Cosmochim. Acta, 66 (2002) 3599-3613.

[55] R.C. Moore, M. Borkowski, M.G. Bronikowski, J.F. Chen, O.S. Pokrovsky, Y.X. Xia, G.R. Choppin, J. Solut. Chem., 28 (1999) 521-531.

[56] N. Rawat, R.S. Sharma, B.S. Tomar, V.K. Manchanda, Thermochim. Acta, 501 (2010) $13-18$

[57] J. Kielland, J. Am. Chem. Soc., 59 (1937) 1675-1678. 
[58] W. Hummel, U. Berner, E. Curti, F.J. Pearson, T. Thoenen, Nagra/PSI chemical thermodynamic data base 01/01, NTB 02-06, NAGRA, 2002, pp. 565.

[59] R. Guillaumont, T. Fanghänel, J. Fuger, I. Grenthe, V. Neck, D.A. Palmer, M. Rand, Chemical Thermodynamics 5. Update on the Chemical Thermodynamics of Uranium, Neptunium, Plutonium, Americium and Technetium, North-Holland, Amsterdam, The Netherlands, 2003.

[60] J.P. Cornard, C. Lapouge, C. Allet-Bodelot, Chem. Phys. Lett., 489 (2010) 164-168.

[61] F.J. Sikora, M.B. McBride, Soil Sci. Soc. Am. J., 54 (1990) 78-86.

[62] J.P. Cornard, C. Lapouge, J. Phys. Chem. A, 110 (2006) 7159-7166.

[63] L.O. Öhman, S. Sjöberg, Acta Chem. Scand. Ser. A, 35 (1981) 201-212.

[64] E. André, C. Lapouge, J.-P. Cornard, Theochem, 806 (2007) 131-140.

[65] L. Boilet, J.P. Cornard, C. Lapouge, J. Phys. Chem. A, 109 (2005) 1952-1960.

[66] B.C. Bhuyan, S.N. Dubey, J. Indian Chem. Soc., 58 (1981) 613-614.

[67] D.G. Kinniburgh, D.M. Cooper, Environ. Sci. Technol., 38 (2004) 3641-3648.

[68] D.G. Kinniburgh, D.M. Cooper, Creating graphical output with PHREEQC, 2011, pp. 584, http://www.phreeplot.org/PhreePlot.pdf.

[69] H. Irving, H. Rossotti, Acta Chem. Scand., 10 (1956) 72-93.

[70] G.R. Choppin, A.J. Graffeo, Inorg. Chem., 4 (1965) 1254-1257. 
[71] G.R. Choppin, P.A. Bertrand, Y. Hasegawa, E.N. Rizkalla, Inorg. Chem., 21 (1982) $3722-3724$.

[72] P. Vitorge, V. Phrommavanh, B. Siboulet, D. You, T. Vercouter, M. Descostes, C.J. Marsden, C. Beaucaire, J.P. Gaudet, C. R. Chimie, 10 (2007) 978-993.

[73] K. Spahiu, J. Bruno, A Selected Thermodynamic Database for REE to be Used in HLNW Performance Assessment Exercises, SKB-TR-95-35, SKB, 1995, pp. 80, http://www.skb.se/upload/publications/pdf/TR95-35webb.pdf.

[74] C.W. Davies, Ion Association, Butterworths, London, UK, 1962.

[75] H. Irving, R.J.P. Williams, D.J. Ferrett, A.E. Williams, J. Chem. Soc., (1954) 3494-3504.

[76] D.J. Macero, H.B. Herman, A.J. Dukat, Anal. Chem., 37 (1965) 675-677.

[77] R. Portanova, L.H.J. Lajunen, M. Tolazzi, J. Piispanen, Pure Appl. Chem., 75 (2003) 495-540.

[78] A. Barkleit, J. Kretzschmar, S. Tsushima, M. Acker, Dalton Trans., 43 (2014) 1122111232.

[79] F.Z. Erdemgil, S. Sanli, N. Sanli, G. Ozkan, J. Barbosa, J. Guiteras, J.L. Beltran, Talanta, 72 (2007) 489-496.

[80] R.M. Smith, A.E. Martell, Critical Stability Constants (V3: Other Organic Ligands), Plenum, New York, 1977. 
[81] W. Hummel, G. Anderegg, L.F. Rao, I. Puigdomènech, O. Tochiyama, Chemical Thermodynamics 9. Chemical Thermodynamics of Compounds and Complexes of U, $\mathrm{Np}, \mathrm{Pu}, \mathrm{Am}, \mathrm{Tc}, \mathrm{Se}, \mathrm{Ni}$ and $\mathrm{Zr}$ with Selected Organic Ligands, Elsevier, Amsterdam, The Netherlands, 2005.

[82] J.L. Kropp, M.W. Windsor, J. Phys. Chem., 71 (1967) 477-482.

[83] A.-S. Chauvin, F. Gumy, D. Imbert, J.-C.G. Bünzli, Spectrosc. Lett., 37 (2004) 517-532.

[84] D.R.M. Rao, N. Rawat, R.M. Sawant, D. Manna, T.K. Ghanty, B.S. Tomar, J. Chem. Thermodynamics, 55 (2012) 67-74.

[85] M. Hilder, M. Lezhnina, M.L. Cole, C.M. Forsyth, P.C. Junk, U.H. Kynast, J. Photochem. Photobiol., A, 217 (2011) 76-86.

[86] C. Moulin, P. Reiller, C. Beaucaire, D. Lemordant, J. Colloid Interface Sci., 157 (1993) 411-417.

[87] C. Moulin, P. Reiller, C. Beaucaire, D. Lemordant, Appl. Spectrosc., 47 (1993) $2172-$ 2174.

[88] I. Grenthe, J. Am. Chem. Soc., 83 (1961) 360-364. 